\title{
E-BOOKS: UM EXERCÍCIO DE DEMOCRACIA PELO CONSUMO DO SABER DIGITAL
}

\section{E-books: a democracy exercise for the consumption of digital knowledge}

Érica de Holanda ${ }^{1}$

\begin{abstract}
Resumo
Neste artigo, propõe-se analisar como o conhecimento torna-se uma fonte de poder na sociedade contemporânea e como o livro eletrônico (e-book) pode ser um meio de comunicação mais igualitário de distribuição do saber comparado aos livros tradicionais, podendo colaborar para a inclusão social de grande parte da população brasileira e levar a novas práticas sociais. Teóricos como Pierre Bourdieu, Milton Santos e Marshall McLuhan são utilizados para elucidar as idéias expostas.
\end{abstract}

Palavras-chaves: comunicação, e-book, livro eletrônico, consumo, democracia.

\begin{abstract}
In this article, it is proposed to analyze how the acknowledge becomes a source of power in the contemporary society and how the electronic book (e-book) can be a more egalitarian way of communication and of information's distribution compared to traditional books, it can collaborate to social inclusion of large part of Brazilian population and lead to new social practices. Theorists as Pierre Boudieu, Milton Santos and Marshall Mcluhan are used to illustrate the ideas exposed.
\end{abstract}

Keywords: communication, e-book, electronic book, consume, democracy

\section{Resumen}

En este artículo se propone analizar como el conoscimiento se torna uma fuente de poder em la sociedad contemporânea y como el libro electrónico (e-book) puede ser ser um meio de comunicación más igualitario em relación a los libros tradicionales, cooperando para la inclusión social de gran parte de la población brasileña y llevar a nuevas practicas sociales. Teóricos como Pierre Bourdieu, Milton Santos y Marshall Mcluhan són utilizados para elucidar las ideas presentadas.

Palabras-clave: comunicación, e-book, libro electrónico, consumo, democracia.

\footnotetext{
${ }^{1}$ Mestrada em Comunicação Social da Universidade do Estado do Rio de Janeiro. Tel: (21) 9724-3089. Rua Magalhães Couto, 68 / 11, Méier, Rio de Janeiro - RJ. Cep: 20735-180
} 


\section{INTRODUÇÃO:}

Na sociedade globalizada contemporânea, o conhecimento é uma fonte de grande poder. Os fluxos de informações determinam o destino de empresas e funcionários, alterando a vida das pessoas e da estrutura da sociedade. Dessa forma, o saber torna-se essencial para a sobrevivência. Contudo, o que predomina atualmente é a concentração do acesso a notícias e a textos científicos por poucos, privilégio mantido também por meio da dificuldade na distribuição desses dados.

O livro tem sido nos últimos séculos um dos principais instrumentos de preservação e de transferência do conhecimento. Entretanto, o consumo desse meio não é democrático, uma vez que os custos para produzi-lo e para obtê-lo ainda são altos. Com o advento dos $e$ books, surge uma esperança no sentido da popularização da leitura, por isso busca-se neste artigo elucidar os potenciais ainda pouco explorados dessa mídia.

\section{O CONHECIMENTO E O PODER}

Conhecimento é poder e isso não é novidade. Desde a elite de escribas egípcios, séculos antes de Cristo, até os atuais investidores nas bolsas de valores, o monopólio de ciências e/ou de informações específicas foi a causa de lucro e status para alguns e, consequentemente, originou certa desigualdade social. A tradição neo-kantiana trata os diferentes universos simbólicos, mito, língua, arte, ciência, como instrumentos de conhecimento e de construção do mundo dos objetos. ${ }^{2} \mathrm{O}$ domínio sobre as formas simbólicas pode legitimar a ordem estabelecida e favorecer uma classe dominante a manter seus privilégios. Bourdieu explica que:

\footnotetext{
É enquanto instrumentos estruturados e estruturantes de comunicação e de conhecimento que os "sistemas simbólicos" cumprem a sua função política de instrumentos de imposição ou de legitimação da dominação, que contribuem para assegurar a dominação de uma classe sobre a outra (violência simbólica) dando o reforço da sua própria força às relações de força que as fundamentam e contribuindo assim, segundo a expressão de Weber, para a "domesticação dos dominados". (BOURDIEU,1989, p.11)
}

Desde, aproximadamente, a década de 1970, com a $3^{\text {a }}$ revolução industrial e a emergência da informática e da robótica, há a flexibilização da importância da habilidade

\footnotetext{
${ }^{2}$ BOURDIEU, Pierre. O Poder Simbólico. Portugal: Difel. 1989.
} 
técnica e do espaço físico em contraposição à emergência do foco na mobilidade e na posse de informações. O saber torna-se instrumento de poder a partir do momento em que não é partilhado com todos, em nome de interesses pessoais ou empresariais. O profissional valorizado é aquele que possui cada vez mais qualificações e "know-how", em detrimento de todos aqueles excluídos do acesso aos locais de ensino apropriados.

Milton Santos indica que uma característica da sociedade contemporânea é "o papel verdadeiramente despótico da informação", a qual é principalmente utilizada "por um punhado de atores em função de seus objetivos particulares" (SANTOS 2000, P.39). Logo, em busca de uma sociedade mais justa e igualitária, é mister a democratização do saber, permitindo o acesso a ele ao maior número de pessoas o possível e, preferencialmente, com um número mínimo de intermediações entre os emissores e os receptores das mensagens.

\section{O LIVRO COMO MEIO DE AQUISIÇÃO DE CONHECIMENTO E AS SUAS RESTRIÇÕES}

Diversos são os meios de difusão do saber, entretanto, desde a invenção da escrita, há a contínua falência da cultura oral como forma de transmissão de conhecimento e emergem os meios de comunicação como principais transmissores de informação. O livro é, inegavelmente, um dos mais tradicionais desses meios e das fontes de saber. Por meio dele, diversos indivíduos podem ter acesso às idéias de pensadores de várias partes do mundo, sendo necessário para isso, às vezes, somente uma tradução do texto original.

Porém, atualmente, no Brasil, o acesso a esse antigo instrumento ainda é restrito às classes sociais mais elevadas. Entre os problemas de seu amplo consumo pela população, estão o seu alto preço e a carência de boas bibliotecas públicas, tanto em termos quantitativos, quanto em qualitativos. Conforme o Instituto Brasileiro de Geografia e Estatística (IBGE), a biblioteca é um dos equipamentos culturais mais importantes do Brasil, presente em cerca de $85 \%$ das cidades brasileiras. Mesmo assim, cerca de 630 municípios brasileiros ainda não têm biblioteca pública e grande parte das existentes possui equipamentos precários, acervos ínfimos ou muito defasados e recursos humanos despreparados para um processo de mediação eficiente na formação de leitores.

Na pesquisa Retrato da leitura no Brasil ${ }^{3}$, realizada em 2001 pela Câmara Brasileira do Livro (CBL), pelo Sindicato Nacional dos Editores de Livros (Snel) e pela Associação

\footnotetext{
${ }^{3}$ Disponível em http://www.cerlalc.org/redplanes/boletin_redplanes/documentos/Noticia1/Retratos_2008.pdf
} 
Brasileira dos Editores de Livros (Abrelivros), foi apontado que o brasileiro lê em média 1,8 livro por ano, índice muito baixo comparado ao de países como a França $(7,0)$, os Estados Unidos $(5,1)$, a Inglaterra $(4,9)$ ou a Colômbia $(2,4)$. Esse dado torna-se ainda mais crítico quando a pesquisa revela que a penetração do livro no país e o acesso a esse objeto cultural são bastante restritos, uma vez que o mercado comprador de livros concentra-se nas mãos de $20 \%$ da população alfabetizada com 14 anos ou mais, na Região Sudeste, nas grandes cidades e metrópoles, nos estratos de renda mais elevada (classe A) e com instrução superior, fato compreensível devido aos altos preços geralmente cobrados por cada livro.

\section{O E-BOOK COMO POSSIBILIDADE DE DEMOCRATIZAÇÃO DA LEITURA}

Contudo, essa realidade de discrepâncias talvez possa ser mudada a partir dos sistemas técnicos atuais. No caso específico da leitura, que é o foco deste artigo, um novo panorama futuro surge com o advento do e-book. O termo de origem inglesa e $\neg$ book é uma abreviação para "electronic book" ou livro eletrônico e trata-se de um livro em mídia eletrônica digital, convertido para esse tipo de mídia ou elaborado originalmente nessa forma (RABAÇA \& BARBOSA 2001). Sua produção não é um fenômeno muito recente e inicia-se com Michael Hart, inventor dos livros eletrônicos em 1971 e fundador do Projeto Gutemberg - cujo objetivo é realizar um esforço voluntário para digitalizar, arquivar e distribuir obras culturais através da digitalização de livros. ${ }^{4}$

Segundo uma reportagem realizada em dezembro de 2008 pelo jornal americano The New York Times, com uma forte campanha lançada por duas importantes empresas que produzem aparelhos específicos para a sua leitura -Amazon e Sony -muitos leitores e editores acreditam que o consumo de e-books pode aumentar exponencialmente. Varejistas do artigo, nos Estados Unidos, asseguram que as vendas triplicaram ou quadruplicaram no último ano. Na Feira do livro de Frankfurt de 2008, os livros eletrônicos foram amplamente oferecidos e com boa repercussão: dos 6 mil expositores presentes nessa edição do evento, cerca de 400 já ofereciam textos para e-books.

O livro eletrônico permite iniciativas inovadoras por seu potencial de distribuição de forma rápida e barata, alcançando lugares onde poderia ser difícil o transporte físico de livros - um fator comum em diversas partes do Brasil que sofrem com a distância e a falta de acesso dos produtos das grandes cidades. Dessa forma, muitos bens culturais poderiam chegar àquela parte da população geralmente excluída das novidades editoriais tanto

\footnotetext{
${ }^{4}$ Para mais informações: www.gutenberg.org
} 
literárias quanto científicas.

\section{O E-BOOK NO CELULAR}

Ampliando as perspectivas dos usos dessa mídia, a revista americana Business Week enfatizou, na edição de 8 de janeiro de 2009, o sucesso dos livros digitais no celular. Na reportagem, é citado que os leitores que vivem viajando preferem o celular. Apesar da tela limitada, atende-se à preferência pela mobilidade de que os computadores e laptops não dispõem, além da economia em relação à compra de um leitor eletrônico. Além disso, assegura-se que está mais fácil conseguir livros pelos telefones celulares, porque as empresas vêm criando páginas na Internet que permitem o download de dezenas de livros, especialmente os clássicos, que não têm proteção de direitos autorais.

O preço também aparece como um outro atrativo, segundo o jornal americano. Enquanto títulos novos como Twilight podem custar tanto quanto um livro em capa mole, muitos clássicos estão disponíveis por US\$ 0,99 ou menos. As editoras estão apostando nos livros digitais para atingir um público maior, pessoas que provavelmente não entrariam em uma livraria. Os lucros obtidos com os $e$-books poderão ser maiores do que a receita gerada pelo livro tradicional porque não há custos de impressão e distribuição.

No Brasil, a distribuição de livros digitais por meio de telefones celulares ainda não está consolidada, porém há um enorme potencial para essa mídia. Em fevereiro de 2009, o total de linhas de telefones celulares chegou a 152.364.986, um índice de aproximadamente 8 celulares para cada 10 habitantes, de acordo com dados divulgados pela Agência Nacional de Telecomunicações (Anatel) - que utiliza como fonte pesquisas do IBGE. Para que esses aparelhos possam receber textos, basta possuírem um simples software (Java), já presente desde a fabricação em muitos deles, ou facilmente adquirido pela internet e compatível com muitos modelos já produzidos.

Já é crescente o uso do celular como central de mídia pelos brasileiros. Em matéria do Valor Online, em janeiro deste ano, constata-se que a música continua sendo o conteúdo mais atrativo e procurado pelos usuários de celulares, mas novas apostas por parte de fabricantes e operadoras começam a surgir no Brasil: filmes, jogos, videoclipes de bandas, audiolivros e livros digitais já estão disponíveis em diversos aparelhos. O modelo de negócio geralmente é baseado em parcerias entre provedores de conteúdo e fabricantes ou operadoras de celular

Desde janeiro, o Brasil já publica livros eletrônicos exclusivos para leitura no 
celular. A Editora Plus (www.editoraplus.org), que estreou em novembro de 2008, é a primeira casa editorial brasileira a realizar esse feito. Desde então, downloads de seus livros podem ser feitos gratuitamente e seu catálogo pode ser lido em computadores, iPhones, smartphones e celulares que aceitem aplicativos Java. A inovação alcança todos os aspectos do livro: os autores pagam apenas as taxas da Biblioteca Nacional para publicar; enquanto revisão, diagramação, capa (e até tradução) são feitas por profissionais voluntários. Os leitores, além de obterem as obras de graça sem necessidade de cadastro, podem comentar, colaborar e até doar dinheiro para os autores.

\section{NOVAS PRÁTICAS E SENSIBILIDADES}

Todo meio introduz novas sociabilidades e percepções em um grupo, mudando as relações dos homens uns com os outros e com si mesmos. McLuhan elucida que

\footnotetext{
as conseqüências sociais e pessoais de qualquer meio - ou seja, de qualquer uma das extensões de nós mesmos - constituem o resultado do novo estalão introduzido em nossas vidas por uma nova tecnologia ou extensão de nós mesmos. (MCLUHAN 1996, p.21)
}

Com o consumo de livros eletrônicos, provavelmente também haverá adaptações sensoriais e administrativas na sociedade como um todo. Primeiramente, o indivíduo lidará com um menor campo de leitura, como a tela de um Palm ou de um celular, com uma visualização muito mais restrita do que a de uma página de um livro. Essa restrição também pode levar a uma leitura mais fragmentada, por serem exibidos poucos caracteres por vez. Além disso, por serem objetos mais portáteis, provavelmente serão utilizados durante trajetos de viagem - preferência já citada pela reportagem da revista Business Week - e, dessa maneira, a leitura será mais interrompida.

Essas mudanças no ato da leitura poderão implicar transformações na compreensão do conteúdo do livro. Pensando ainda além: se a fragmentação da leitura e a menor quantidade de palavras na tela tornarem-se um hábito no momento de ler, a leitura de um livro impresso tradicional pode se tornar uma dificuldade para as gerações futuras. Julgar o mérito ou não dessas modificações será um tema para discussões posteriores que não abordaremos neste artigo.

Em termos comerciais, o e-book demanda uma nova forma de produção, distribuição e cobrança pelo acesso ao livro. Como não são necessários a impressão - um dos maiores custos dos livros tradicionais -, o transporte físico ou o estoque de muitos objetos, os custos do lançamento de um livro eletrônico caem expressivamente em relação àquele impresso. 
Assim, muito mais autores poderiam ter a possibilidade de lançar suas obras a um grande público, sem precisar de investimentos maciços. Dessa forma, democratiza-se a produção do conhecimento, permitindo que autores locais e pouco conhecidos possam projetar seus textos para milhares de pessoas sem a necessidade de patrocinadores.

As desigualdades no acesso ao conhecimento também poderão ser suplantadas, uma vez que, com menor custo de produção, os livros eletrônicos chegariam à população com preços muito inferiores aos dos impressos atualmente. Logo, um novo público poderia ser atendido - estudantes e pessoas de baixa renda - e os leitores habituais poderiam adquirir mais unidades por ano. Com a ascensão da quantidade de livros vendidos, os autores e as editoras lucrariam e poder-se-ia impulsionar a produção textual a patamares inimagináveis. Com os e-books nos celulares facilita-se ainda mais o acesso a essa mídia, pois não é um suporte caro e a população já está acostumada com o seu uso, visto os altos índices de usuários supracitados.

O problema na distribuição virtual insere-se na questão já existente em relação à música digital: a pirataria. Assim, como programas em áudio e vídeo, textos são facilmente copiados e transmitidos pela internet. Cabe às novas editoras virtuais elaborar formas seguras de vender livros on-line sem que os direitos autorais e de distribuição sejam violados.

Conscientizar a população dos malefícios causados pela cópia ilegal é uma ação que já vem sendo tomada, sobretudo pela indústria audiovisual, mas até agora com poucos resultados eficazes. No caso dos e-books, o baixo preço pode ser um atrativo para o consumidor consciente, diferente da situação dos CDs e DVDs, que ainda custam muito caro, desestimulando a procura pelo original em vez da cópia.

\section{CONCLUSÃO}

A democratização do conhecimento nunca foi tão imperativa como na sociedade globalizada em que vivemos. Uma vez que a posse de informações pode selar o destino de um homem, o acesso a elas torna-se essencial para definir seu modo de vida. Consequentemente, é vital discutir os meios necessários e possíveis para que o saber possa circular na sociedade de forma igualitária e coerente com as necessidades demandadas pelo mercado de trabalho da economia formal. A tecnologia é um caminho para alcançar uma transformação no paradigma atual de extremo desequilíbrio no nível do saber. 
Os sistemas técnicos de que se valem os atuais atores hegemônicos estão sendo utilizados para reduzir o escopo da vida humana sobre o planeta. No entanto, jamais houve na história sistemas tão propícios a facilitar a vida e proporcionar a felicidade dos homens. A materialidade que o mundo da globalização está recriando permite um uso radicalmente diferente daquele que era o da base material da industrialização e do imperialismo. (SANTOS, 2000. p.164)

No século XXI, a leitura continua sendo um dos mais importantes meios de transmissão de conhecimento e, desde rochas até leitores digitais, os suportes para mensagens escritas adaptaram-se aos anseios da humanidade, transformando seus costumes, concomitantemente. Nesse contexto, os livros eletrônicos surgem como uma potencialidade para a distribuição de textos, independente dos locais onde a editora e o leitor estejam. Também possuem a capacidade de minimizar as barreiras financeiras impostas pelo mercado editorial, atingindo também leitores não habituais, uma vez que podem ser oferecidos a preços bem menores do que os de livros tradicionais e lidos com aparelhos também relativamente baratos, como os celulares.

Com o lançamento de cada obra facilitado - diminuindo os custos e o tempo do processo - abrem-se novas possibilidades para escritores desconhecidos, locais e de baixa renda alcançarem um público abrangente e diversificado. A maior portabilidade das obras e a fragmentação da leitura podem levar as futuras gerações a adquirirem novas práticas em relação ao ato de ler e à manipulação dos livros tradicionais.

A popularização dos livros eletrônicos certamente trará consequências a todo o processo de produção e consumo de textos. O potencial dessa mídia ainda não está plenamente explorado, porém já demonstra ser uma possibilidade de acesso de novos escritores e leitores ao grande mercado editorial. Além disso, os e-books podem ser um caminho para a proliferação menos desigual do saber a nível global, auxiliando a ascensão social de muitos dos excluídos existentes na sociedade globalizada contemporânea.

\section{REFERÊNCIAS BIBLIOGRÁFICAS:}

AHAL, Manuela; MOREIRA, Talita (16 jan. 2009). "Cresce uso do celular como central de mídia" in Valor Econômico Online. Link restrito a assinantes.

BOURDIEU, Pierre. O Poder Simbólico. Portugal: Difel. 1989.

CRESCENTI, Marcelo. E-books são estrelas da feira do livro de Frankfurt in Valor Econômico Online, 16, Nov/2008. Link restrito a assinantes.

FILHO, Daniel Aarão; FERREIRA, Jorge; ZENHA, Celeste (org). O século XX Volume I: 
O tempo das certezas. $3^{\text {a }}$ ed. Rio de Janeiro: Civilização Brasileira, 2006.

KHARIF, Olga. "Digital Books via Cell Phone” in Business Week Online, 8, jan/2009. Disponível em: <http://www.businessweek.com/print/magazine/content/ 09_03/b4116053929062.htm>

MCLUHAN, Marshall. Os meios de comunicação como extensões do homem. $8^{\mathrm{a}}$ ed. São Paulo: Cultrix, 1996.

RABAÇA, Carlos; BARBOSA, Gustavo. Dicionário de Comunicação. Rio de Janeiro: Campus, 2001.

SANTOS, Milton. Por uma outra globalização: do pensamento único a consciência universal. $4^{\text {a }}$ ed. Rio de Janeiro: Record, 2000.

. Metamorfoses do Espaço Habitado. $2^{\text {a }}$ ed. São Paulo: Editora Hucitec, 1991

STONE, Brad; RICH, Motoko. "Turning Page, E-Books Start to Take Hold" in The New York Times Online, 23, dez/2008. Disponível em: http://www.nytimes.com/ 2008/12/24/technology/24kindle.html?_r=3\&th\&emc=th.

<http://www.gutenberg.org>. Acesso entre: 13/05/2009 e 26/05/2009

$<$ http://www.cerlalc.org>. Acesso entre: 13/05/2009 e 26/05/2009

<http://www.ibge.gov.br>. Acesso entre: 13/05/2009 e 26/05/2009

Artigo recebido em 25/8/2009.

Aprovado em 25/9/2009. 